\title{
Removal of tetracycline antibiotics from aqueous solution by amino-Fe (III) functionalized SBA15
}

\author{
Ziyang Zhang ${ }^{\mathrm{a}, \mathrm{b}}$, Huachun Lan ${ }^{\mathrm{a}}$, Huijuan Liu ${ }^{\mathrm{a}, *}$, Jiuhui $\mathbf{Q u}^{\mathrm{a}}$ \\ a Key Laboratory of Drinking Water Science and Technology, Research Center for Eco-Environmental Sciences, Chinese Academy of Sciences, Beijing 100085, \\ China \\ ${ }^{\mathrm{b}}$ University of Chinese Academy of Sciences, Beijing 100039, China
}

\section{H I G H L I G H T S}

- Amino-Fe (III) functionalized SBA15 was prepared.

- The adsorbent had high adsorption efficiency for all three TCs.

- The differences in the removal trends may be attributed to their $\mathrm{p} K_{\mathrm{a}}$ values.

- The complexation of Fe (III) and TCs improved the sorption capacity.

\section{A R T I C L E I N F O}

\section{Article history:}

Received 17 November 2014

Received in revised form 30 January 2015

Accepted 2 February 2015

Available online 17 February 2015

\section{Keywords:}

Adsorption

Mesoporous silica

Functionalized SBA15

Tetracyclines

Complexation

\section{G R A P H I C A L A B S T R A C T}

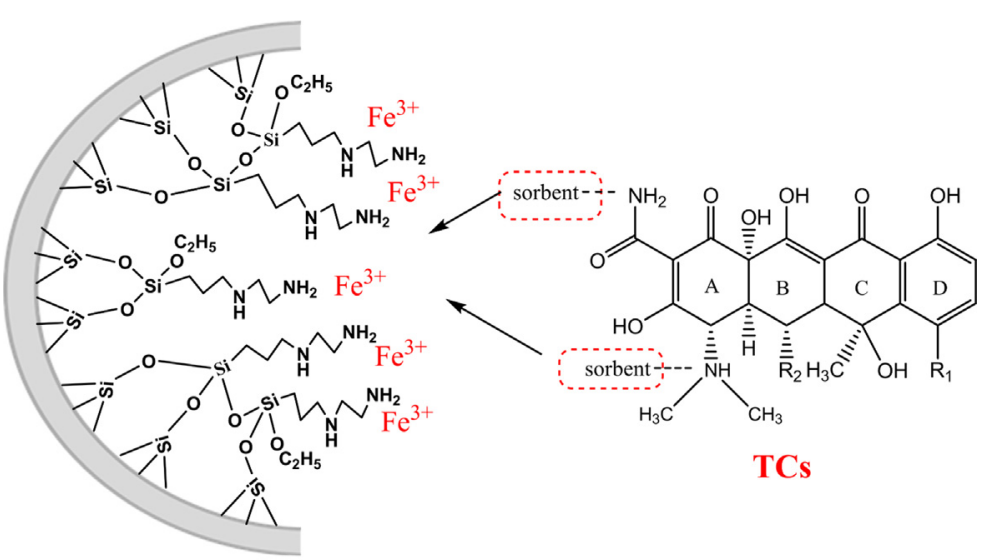

Fe-N, N-SBA15

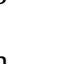




\section{Introduction}

Antibiotics are widely used as human infectious disease medicines, veterinary medicines and animal husbandry growth promoters [1,2]. However, most of the antibiotics are poorly absorbed and metabolized by humans and animals after intake, so that about $30-90 \%$ of administered compounds are released into the environment [3]. In addition, antibiotics are discharged into rivers in the effluents of wastewater treatment plants and feces from animal feeding operations [3-5].

Tetracyclines (TCs), including tetracycline (TC), oxytetracycline (OTC) and chlortetracycline (CTC), constitute one of the most important families of antibiotics. Recently, TCs have been detected in most bodies of water influenced by raw or treated wastewater, including rivers, streams, lakes and ground waters, many of which are used as drinking water sources [6-9]. The increased presence of TCs in the environment raises concerns about their potential to foster the selection of resistant bacteria and resistance genes in the long term as well as serious impacts on the ecosystem [10-12]. As shown in Fig. 1, TCs possess tricarbonylamide, phenolic diketone and dimethylamine groups that confer a marked $\mathrm{pH}$ dependent behavior on solubility, and TCs exist as cationic $(+00)$, zwitterionic $( \pm 0)$, and anionic species ( \pm or $0-$ ) under different $\mathrm{pH}$ conditions, which introduces more complexity into their behavior in the environment [13]. Consequently, the effective control of the TCs has attracted increasing concern, due to their potential risk and ineffective removal by conventional water treatment. It is of great importance to explore efficient treatment technologies for TCs removal.

Adsorption, due to its simplicity, eco-friendliness and high efficiency, is one of the most important methods for TCs removal $[1,14]$. Many adsorbents such as soils, montmorillonite, magnetic porous carbon, and surface-functionalized mesoporous silica have been used to adsorb TCs from water $[1,13,15,16]$. In addition, previous metal-antibiotic interactions studies showed that iron could form stable complexes with TCs. Barbooti et al. found that the ferric ions in clay could form stable complexes with OTC, improving the adsorption characteristics [15]. Özge Hanay et al. proved that increasing iron dose enhanced TC and OTC removal efficiency [17]. Raquel et al. also confirmed that the surface complexation mechanism could be described by the interaction of divalent anion species of OTC with the iron oxide surface [18].

In recent years, ordered mesoporous silica, such as SBA15, has attracted considerable attention from researchers due to its uniform mesoporous structure and high surface area, which can enhance the interaction between the solid surface and guest molecules $[19,20]$. Furthermore, the pore size of mesoporous silica is large enough to enable facile chemical functionalization of the high density of silanol groups on the pore surface, making mesoporous silica suitable for a wide range of applications in adsorption [20,21]. Among new functionalized mesoporous silica, amino-functionalized silica is very important due to its excellent chelating ability with heavy metals, but its use as an adsorbent to remove TCs is limited because of the low adsorption capacity.

In this paper, to improve the adsorption of TCs on ordered mesoporous silica, we prepared functionalized SBA15 with both amino groups and Fe (III) (named Fe-N,N-SBA15) for TCs removal. The adsorbent is prepared first by grafting $\mathrm{N}-(2-$ aminoethyl)-3-aminopropyltriethoxysilane onto SBA15, followed by the coordination of Fe (III) on the adsorbent. The adsorption behavior and mechanism of TCs onto Fe-N,N-SBA15 were then investigated. The effects of the solution $\mathrm{pH}$ and ionic strength on TCs adsorption, adsorption kinetics, adsorption isotherms and thermodynamic parameters were studied. The adsorption mechanism was investigated by Fourier transformed infrared spectroscopy (FTIR) and X-ray photoelectron spectroscopy (XPS).

\section{Experimental}

\subsection{Materials and chemicals}

Hydrochloride salts of tetracycline, oxytetracycline and chlortetracycline were procured from Sigma Co. and used without further purification. Tetraethyl orthosilicate (TEOS, 98\%), Pluronic $\mathrm{P} 123\left(\mathrm{PEO}_{20} \mathrm{PPO}_{70} \mathrm{PEO}_{20}\right.$, Mav = 5800) and $\mathrm{N}$-(2-aminoethyl)-3aminopropyltriethoxysilane (96\%) was obtained from Alfa Aesar Corp. Acetonitrile and methanol were HPLC grade and obtained from Fisher Scientific Corp. Other chemicals including sodium hydroxide, hydrochloric acid, ferric chloride, isopropanol, and oxalic acid were of analytical grade. All solutions were prepared in high-purity water (Milli-Q).

\subsection{Sorbent preparation}

Mesoporous silica SBA15 was prepared according to Zhao et al., using TEOS as the silica source and pluronic P123 as the templating reagent [22]. The amino-functionalized SBA15 was prepared in a step-wise fashion using grafting techniques. $3 \mathrm{~g}$ of SBA15 was suspended in toluene and an excess amount of $\mathrm{N}$-(2-aminoethyl)3-aminopropyltriethoxysilane was added drop-wise to the slurry and stirred under reflux at about $100^{\circ} \mathrm{C}$ for $24 \mathrm{~h}$. The precipitate was filtered, washed with dry toluene followed by isopropanol and dried overnight, and the product was designated as N,N-SBA15. Incorporation of Fe (III) on the sorbent were carried out by adding $1.5 \mathrm{~g} \mathrm{~N}, \mathrm{~N}-\mathrm{SBA} 15$ to a $0.1 \mathrm{~mol} \mathrm{~L}^{-1}$ isopropanol solution of ferric chloride and reacted for $24 \mathrm{~h}$. The mixture was filtered, washed with isopropanol and dried overnight. The product was named as Fe$\mathrm{N}, \mathrm{N}-\mathrm{SBA} 15$. Previous results showed that the amino group and $\mathrm{Fe}$ (III) were successfully grated on SBA15, and that the mesoporous structural order was still maintained after the functionalization. Nitrogen gas sorption isotherms and textural properties were analyzed and the surface area, pore volume and pore size were $245.29 \mathrm{~m}^{2} / \mathrm{g}, 0.38 \mathrm{~cm}^{3} / \mathrm{g}$ and $6.12 \mathrm{~nm}$. Elemental analysis of

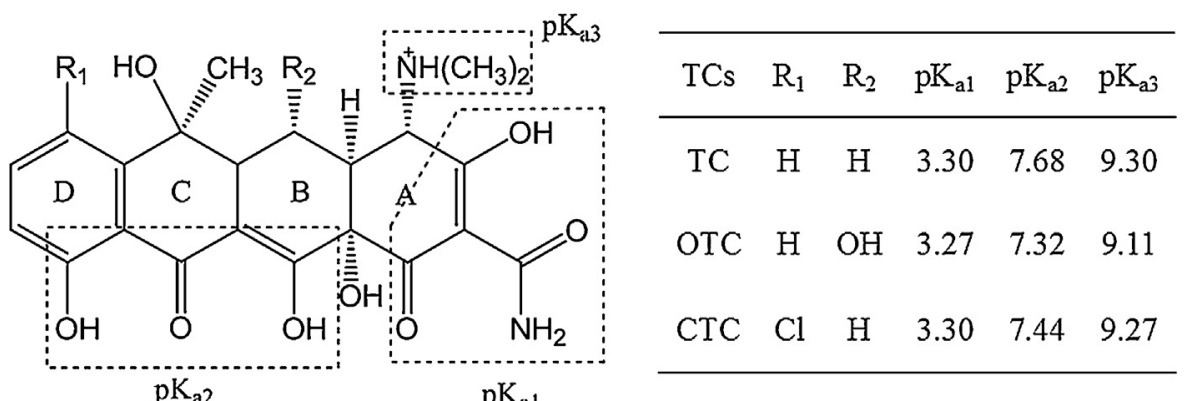

Fig. 1. Molecular structure and ionization constants of TCs. 
Fe-N,N-SBA15 revealed a mass composition of $9.16 \mathrm{wt} \% \mathrm{C}, 2.56 \mathrm{wt} \%$ $\mathrm{N}$ and $0.27 \mathrm{wt} \% \mathrm{Fe}$.

\subsection{Characterization techniques}

A Tenson 27 FTIR Spectrometer (Bruker, Germany) was used to determine the vibrational frequency changes in the functional groups of virgin and TCs-loaded Fe-N,N-SBA15. The samples of virgin and TCs-loaded adsorbents were mixed with $\mathrm{KBr}$ at an approximate ratio of $1 / 150$ (adsorbent/KBr) and then ground in an agate mortar. The resulting mixture was pressed at 10 tons for $2 \mathrm{~min}$ to form a pellet, and was then characterized.

Chemical analyses of the virgin and TCs-loaded adsorbents were conducted by XPS (Kratos AXIS ULTRA, UK). The XPS spectra were obtained by applying a monochromatic $\mathrm{Al} K \alpha$ (1486.7) X-ray energy source operated at $15 \mathrm{kV}$ and $10 \mathrm{~mA}$. The software package Vision (PR2.1.3) and CasaXPS (2.3.12Dev7) were used to fit the XPS spectra peaks.

\subsection{Adsorption batch experiments}

All sample tubes or flasks were wrapped in foil to inhibit photodegradation. For the kinetic adsorption experimental study, $0.5 \mathrm{~g}$ $\mathrm{Fe}-\mathrm{N}, \mathrm{N}-\mathrm{SBA} 15$ was added into $500 \mathrm{ml}$ solutions in glass flasks containing with each of the TCs at initial concentration $0.1 \mathrm{mmol} \mathrm{L}^{-1}$. The mixed solutions were shaken at a speed of $150 \mathrm{rpm}$, and hydrochloric acid and sodium hydroxide were used to adjust the solution $\mathrm{pH}$ to the desired values. Samples were collected at appropriate time intervals and filtered through a $0.45 \mu \mathrm{m}$ membrane filter, and analyzed for the TC concentration.

In the $\mathrm{pH}$ effect, ionic strength and adsorption isotherm experiments, polypropylene tubes were used. The $\mathrm{pH}$ effect experiments were carried out by adding a mass of $25 \mathrm{mg}$ sorbent into $25 \mathrm{ml}$ solutions containing TCs with the initial concentration of $0.1 \mathrm{mmol} \mathrm{L}^{-1}$. The mixed solutions were shaken at a speed of $150 \mathrm{rpm}$ for $24 \mathrm{~h}$. The solution $\mathrm{pH}$ was adjusted to different values between 3 and 9 using hydrochloric acid and sodium hydroxide. After the adsorption, the samples were filtered through a $0.45 \mu \mathrm{m}$ membrane filter and analyzed.

For ionic strength experiments, a series of $0.1 \mathrm{mmol} \mathrm{L}^{-1} \mathrm{TCs}$ solutions with ionic strength from 0 to $100 \mathrm{mmol} \mathrm{L}^{-1} \mathrm{NaCl}$ were prepared. The solution $\mathrm{pH}$ was kept at $5.0 \pm 0.1$. Other adsorption procedures were the same as those in the above $\mathrm{pH}$ effect experiments.

Adsorption isotherm experiments of the TCs were investigated at 298,308 and $318 \mathrm{~K}$ by adding $25 \mathrm{mg}$ adsorbent to $25 \mathrm{ml}$ solutions with initial concentrations of TCs of $0,0.01,0.03,0.05,0.07$, $0.1,0.15$ and $0.2 \mathrm{mmol} \mathrm{L}^{-1}$. The solution $\mathrm{pH}$ was kept at $5.0 \pm 0.1$. Other experimental conditions were conducted as in the pH effect experiment.

The TC concentrations were determined by HPLC (Agilent 1260 , USA) at a wavelength of $360 \mathrm{~nm}$. The mobile phase was a mixture of $10 \mathrm{mmol} \mathrm{L}^{-1}$ oxalic acid-acetonitrile-methanol $(67: 22: 11, \mathrm{v} / \mathrm{v})$ at a flow rate of $1 \mathrm{ml} \mathrm{min}^{-1}$.

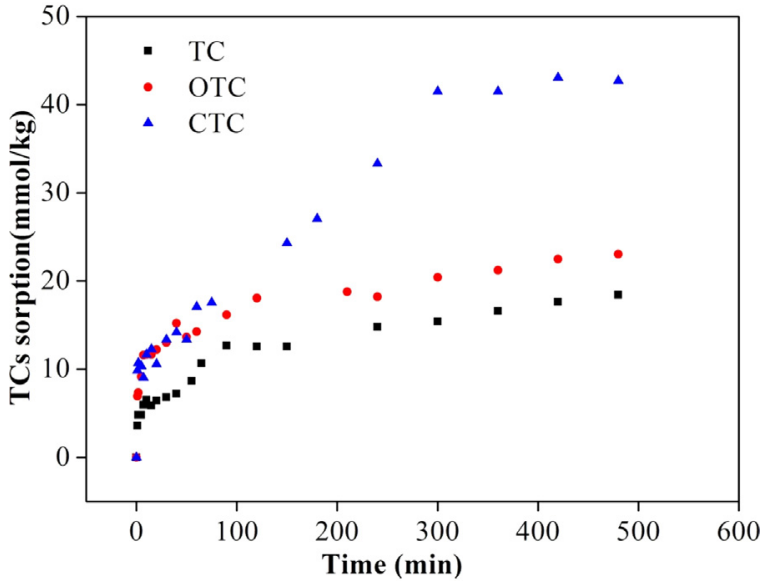

Fig. 2. Adsorption kinetics of $\mathrm{TCs}$ on Fe-N,N-SBA15. Experimental conditions: $[\mathrm{TCs}]_{0}=0.1 \mathrm{mmol} \mathrm{L}^{-1}, \mathrm{~m}=1 \mathrm{~g} \mathrm{~L}^{-1}, \mathrm{~T}=298 \mathrm{~K},[\mathrm{NaCl}]=10 \mathrm{mmol} \mathrm{L}^{-1}, \mathrm{pH}=5.0 \pm 0.1$.

\section{Results and discussion}

\subsection{Adsorption kinetics of TCs on Fe-N,N-SBA15}

The adsorption kinetics of TCs onto Fe-N,N-SBA15 are shown in Fig. 2. Most TC and OTC were adsorbed rapidly in $100 \mathrm{~min}$, followed by a relatively slow process, and achieved equilibrium with $6 \mathrm{~h}$. CTC was adsorbed quickly in $5 \mathrm{~h}$ and achieved equilibrium in $6 \mathrm{~h}$ as well. The rapid adsorption observed was probably due to the abundant availability of sorption sites on the surface of the sorbent. The kinetic data were fitted with pseudo-first-order and pseudo-second-order models, which describe mononuclear and binuclear adsorption concerning the adsorbent capacity, respectively $[1,23]$. The kinetic parameters are listed in Table 1 . For all TCs, the pseudo-second-order model fitted better with higher correlation coefficients. The good fit supported the assumption that adsorption of TCs on Fe-N,N-SBA15 was controlled by chemical sorption [24]. The adsorption rate constant $k_{2}$ followed the order OTC $>$ TC $>$ CTC, suggesting that OTC was adsorbed onto Fe-N,NSBA15 more quickly. But comparing the $Q_{e}$, the amount of CTC adsorbed was the largest among the three TCs. This was consistent with the sorption of TCs on soil clays, mainly caused by the presence of a chlorine atom in $\mathrm{R}_{1}$ which could lower the $\mathrm{p} K_{\mathrm{a}}$ of the phenolic diketone moiety and increase the water solubility [25]. Compared with TC, CTC and OTC had a chlorine atom and hydroxyl group at $R_{1}$ and $R_{2}$, respectively, which may affect the properties of TCs and influence their adsorption on the sorbent.

\subsection{Effect of $\mathrm{pH}$ and ionic strength on the adsorption}

Effect of $\mathrm{pH}$ and ionic strength on the adsorption of TC onto Fe$\mathrm{N}, \mathrm{N}-\mathrm{SBA} 15$ are showed in Fig. 3. As listed in Fig. 3(a), the adsorption of TCs onto Fe-N,N-SBA15 was greatly influenced by the solution $\mathrm{pH}$ values. The adsorption increased with increasing $\mathrm{pH}$ and reached a maximum at approximately $\mathrm{pH} 5.2,4.4$ and 5.6 for TC, OTC, and $\mathrm{CTC}$, respectively, then decreased with further increase in $\mathrm{pH}$ values. The observed results were associated with the characteristics

Table 1

Values of the pseudo-first-order and pseudo-second-order constants of TCs adsorption on the sorbent

\begin{tabular}{|c|c|c|c|c|c|c|}
\hline & \multicolumn{3}{|c|}{ Pseudo-first-order } & \multicolumn{3}{|c|}{ Pseudo-second-order } \\
\hline & $Q_{e}\left(\mathrm{mmol} \mathrm{kg}^{-1}\right)$ & $k_{1}\left(\min ^{-1}\right)$ & $R^{2}$ & $Q_{e}\left(\mathrm{mmol} \mathrm{kg}^{-1}\right)$ & $k_{2}\left(\mathrm{mmol} \mathrm{kg}^{-1} \mathrm{~min}^{-1}\right)$ & $R^{2}$ \\
\hline TC & 13.69 & 0.006 & 0.95 & 18.34 & 0.0015 & 0.97 \\
\hline OTC & 13.72 & 0.006 & 0.96 & 22.57 & 0.0022 & 0.98 \\
\hline CTC & 39.95 & 0.008 & 0.88 & 45.45 & 0.00035 & 0.90 \\
\hline
\end{tabular}



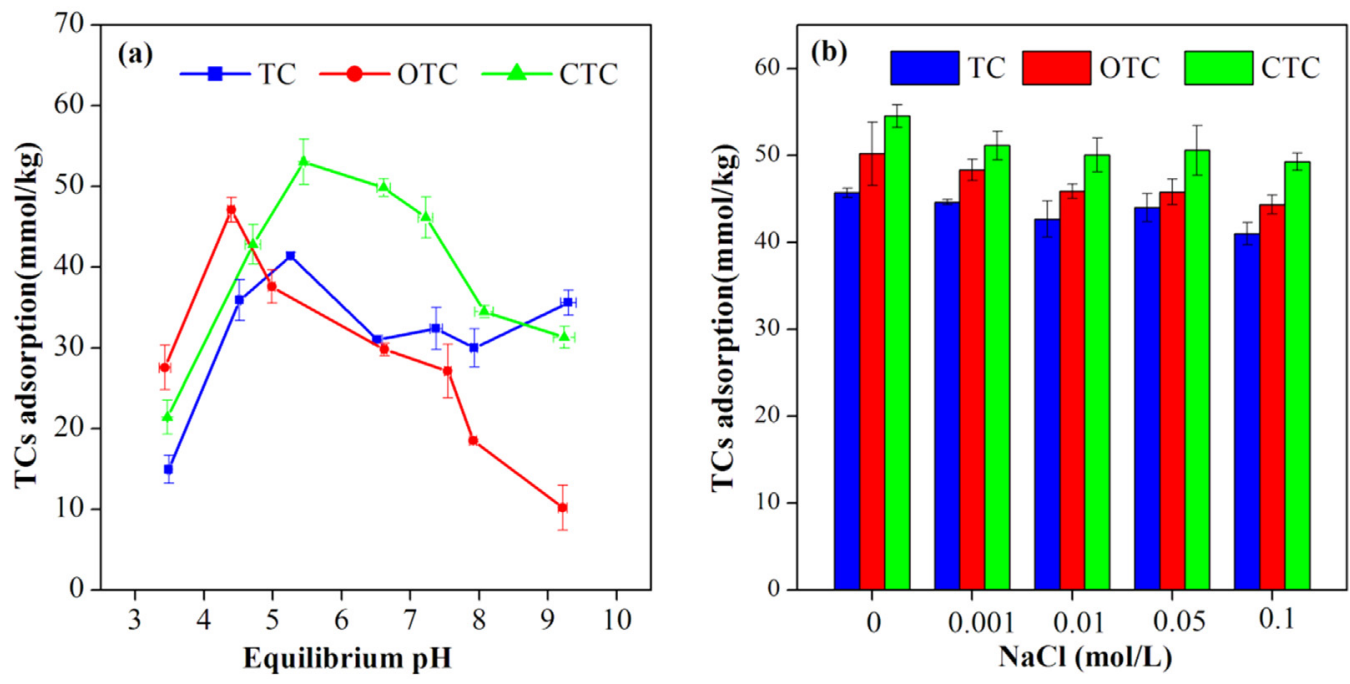

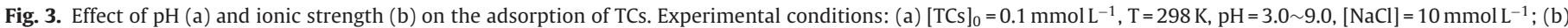
$[\mathrm{TCs}]_{0}=0.1 \mathrm{mmol} \mathrm{L}^{-1}, \mathrm{~T}=298 \mathrm{~K}, \mathrm{pH}=5.0 \pm 0.1,[\mathrm{NaCl}]=0 \sim 100 \mathrm{mmol} \mathrm{L}^{-1}$.

of the TCs and the adsorbent. Fig. S1 shows that the zero point charge of the Fe-N,N-SBA15 was approximately at pH 8.9. TCs are amphoteric compounds with multiple functional groups, thus may predominantly exist as a cation $(+00)(\mathrm{pH}<3.3)$, zwitterion $( \pm 0)$ $(3.3<\mathrm{pH}<7.6)$, and anion $( \pm$ or $0-)(\mathrm{pH}>7.6)$ (Fig. S2) [13]. In the case of pH below 4.0 and over 9.0 , about $20 \mathrm{mmol} \mathrm{kg}^{-1}$ of the added TCs were adsorbed due to the unfavorable electrostatic interactions between TCs molecules and adsorbent surfaces, which suggested that surface complexation may be the dominant mechanism for TCs sorption onto the sorbent [18]. As the $\mathrm{pH}$ increased from 3.0, the interaction between TCs and sorbent increased mainly attributed to a decrease in $\mathrm{TC}^{+00}$ concentration and increase in $\mathrm{TC}^{ \pm 0}$ concentration. When the $\mathrm{pH}$ was in the range of 4.5-6.5, the maximum adsorption of TCs was obtained, mainly caused by surface complexation of $\mathrm{TC}^{ \pm 0}$, which had its highest concentration in this $\mathrm{pH}$ range (Fig. S2). As the concentration of $\mathrm{TC}^{ \pm}, \mathrm{TC}^{0-}$ increased at higher $\mathrm{pH}$, a progressive decrease in adsorption was observed which could be attributed to the decreased electrostatic attraction between the negatively charged TCs and the adsorbent. After TCs adsorption, the increasing negative charge of the sorbent surface suggested that the interaction between TCs and adsorbent was mainly caused by surface complexation [26,27]. The small differences in the removal trends of three TCs at different $\mathrm{pH}$ may be attributed to their $\mathrm{p} K_{\mathrm{a}}$ values as influenced by the characteristics of the chemical groups at the $R_{1}$ and $R_{2}$ positions of the TC molecules (Fig. 1).

Fig. 3(b) shows that the concentration of $\mathrm{NaCl}$ had little effect on the adsorption of TCs on Fe-N,N-SBA15 when ionic strength increased from 0 to $100 \mathrm{mmol} \mathrm{L}^{-1}$. It has been reported that inner-sphere complexes are hardly influenced by changes in ionic strength, where outer-sphere complexes are greatly influenced $[28,29]$. Hence, the adsorption of TCs on Fe-N,N-SBA15 may be related to the formation of inner-sphere surface complexes between adsorbate and adsorbent, consistent with the report by $\mathrm{Gu}$ et al. that TC forms inner-sphere complexes with both $\mathrm{Fe}$ and $\mathrm{Al}$ hydrous oxides [2].

\subsection{Adsorption isotherms}

The adsorption isotherm is critically important in designing an adsorption system. Adsorption isotherms of TCs onto Fe-N,NSBA15 at pH 5.0 are plotted in Fig. 4. The sorption data were fitted by the Langmuir and Freundlich equations [23], and the calculated parameters are summarized in Table 2. It was found that the

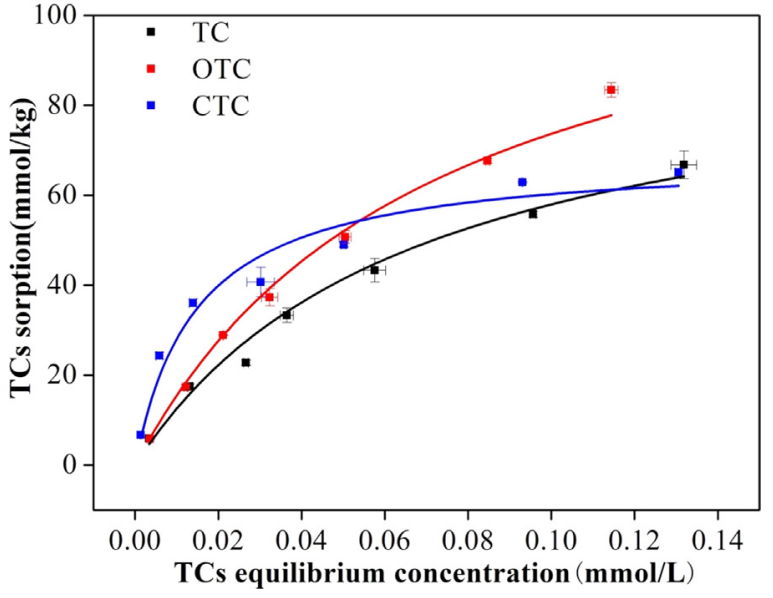

Fig. 4. Adsorption isotherms of $\mathrm{TCs}$ on Fe-N,N-SBA15. Experimental conditions: $[\mathrm{TCs}]_{0}=0-0.2 \mathrm{mmol} \mathrm{L}^{-1}, \mathrm{~m}=1 \mathrm{~g} \mathrm{~L}^{-1}, \mathrm{~T}=298 \mathrm{~K}, \mathrm{pH}=5.0 \pm 0.1,[\mathrm{NaCl}]=10 \mathrm{mmol} \mathrm{L}^{-1}$.

Langmuir model provided a better fit to the observed data for the TCs, with high correlation coefficients $\left(R^{2}=0.98\right)$. The maximum OTC, TC and CTC sorption capacities $\left(Q_{\max }\right)$ were $143.31,96.91$ and $69.15 \mathrm{mmol} \mathrm{kg}^{-1}$, respectively. The values of $1 / n$ were less than 1.0 for all TCs, suggesting that the adsorbent was favorable for the removal of TCs from aqueous solution [23].

It was reported that the sorption capacity of TCs on magnetic porous carbon, microscale zerovalent iron, cross-linked chitosan and hydrophilic molecularly imprinted polymers were $53 \mathrm{mmol} \mathrm{kg}^{-1}$ [1], $49 \mathrm{mmol} \mathrm{kg}^{-1}$ [17], $43 \mathrm{mmol} \mathrm{kg}^{-1}$ [30], and 23-54 mmol kg-1, respectively [24]. The current results clearly indicate that the Fe-N,N-SBA15 sorbent developed in this study has great potential for removal of antibiotics from aqueous environments.

Table 2

Langmuir and Freundlich parameters for the adsorption of TCs on Fe-N,N-SBA15

\begin{tabular}{|c|c|c|c|c|c|c|}
\hline & \multicolumn{3}{|l|}{ Langmuir } & \multicolumn{3}{|c|}{ Freundlich } \\
\hline & $Q_{\max }\left(\mathrm{mmol} \mathrm{kg}^{-1}\right)$ & $b\left(\mathrm{Lmg}^{-1}\right)$ & $R^{2}$ & $n$ & $K_{f}$ & $R^{2}$ \\
\hline TC & 96.91 & 0.067 & 0.98 & 1.51 & 271.77 & 0.93 \\
\hline OTC & 143.31 & 0.088 & 0.98 & 1.31 & 478.01 & 0.97 \\
\hline CTC & 69.15 & 0.015 & 0.98 & 2.17 & 195.35 & 0.89 \\
\hline
\end{tabular}


Table 3

Thermodynamic parameters for the adsorption of TC onto Fe-N,N-SBA15.

\begin{tabular}{|c|c|c|c|c|c|c|}
\hline & Temperature (K) & $K_{c}\left(\mathrm{Lg}^{-1}\right)$ & $\Delta G^{\circ}\left(\mathrm{kJ} \mathrm{mol}^{-1}\right)$ & $\Delta H^{\circ}\left(\mathrm{kJ} \mathrm{mol}^{-1}\right)$ & $\Delta S^{\circ}\left(\mathrm{kJ} \mathrm{mol}^{-1} \mathrm{~K}^{-1}\right)$ & $R^{2}$ \\
\hline \multirow{3}{*}{ TC } & 298 & 0.51 & 1.53 & \multirow{3}{*}{35.77} & \multirow{3}{*}{0.11} & \multirow{3}{*}{0.99} \\
\hline & 308 & 0.87 & 0.39 & & & \\
\hline & 318 & 1.26 & -0.76 & & & \\
\hline \multirow{3}{*}{ OTC } & 298 & 1.11 & -0.15 & \multirow{3}{*}{43.42} & \multirow{3}{*}{0.14} & \multirow{3}{*}{0.97} \\
\hline & 308 & 1.71 & -1.61 & & & \\
\hline & 318 & 3.35 & -3.07 & & & \\
\hline \multirow{3}{*}{ CTC } & 298 & 1.56 & -0.73 & \multirow{3}{*}{46.75} & \multirow{3}{*}{0.16} & \multirow{3}{*}{0.92} \\
\hline & 308 & 1.80 & -2.32 & & & \\
\hline & 318 & 5.10 & -3.91 & & & \\
\hline
\end{tabular}

\subsection{Adsorption thermodynamics}

To study the adsorption of TCs on Fe-N,N-SBA15 further, the temperature effect on the adsorption process is investigated and the thermodynamic parameters such as the Gibbs free energy $\left(\Delta G^{\circ}\right)$, the enthalpy $\left(\Delta H^{\circ}\right)$, and the entropy $\left(\Delta S^{\circ}\right)$ were calculated [1]. Qualitative estimates of $\Delta H^{\circ}$ and $\Delta S^{\circ}$ can be obtained from the slope and intercept of $\ln K_{d}$ vs $1 / T$ as shown in Fig. S3. The resulting thermodynamic parameters are presented in Table 3. The positive values of $\Delta H^{\circ}\left(35.77,43.42\right.$, and $\left.46.57 \mathrm{~kJ} \mathrm{~mol}^{-1}\right)$ for the TCs indicated the endothermic nature of the overall adsorption process. As $\Delta H^{\circ}$ was in the range of $30-70 \mathrm{~kJ} \mathrm{~mol}^{-1}$, the adsorption of TCs on the sorbent was considered to be chemisorption [16]. The endothermic characteristic revealed that the adsorption process was more favorable at higher temperature. The positive values of $\Delta S^{\circ}$ were consistent with the fact that the adsorption process was irreversible and favored sorption. The spontaneity of the adsorption process was illustrated by the negative values of $\Delta G^{\circ}$. Furthermore, the value of $\Delta G^{\circ}$ decreased with increasing temperature, indicating that the reaction between TCs and adsorbent was more favorable at higher temperatures. The results were consistent with those for the adsorption of TC on magnetic porous carbon [1].

\subsection{Adsorption mechanism}

To further investigate the adsorption mechanism of TCs on FeN,N-SBA15, the FTIR and XPS data for the adsorbents before and after the adsorption of TCs were analyzed.

FTIR spectra of the adsorbents are shown in Fig. 5. Since the most characteristic region of the TCs spectrum occurred between 1400 and $1700 \mathrm{~cm}^{-1}$, only this region was interpreted in detail. As the spectra of TC, OTC and CTC had no differences, only the FTIR spectra of TC are shown.

Peak assignments for TC (Fig. 5a) followed the study of $\mathrm{Gu}$ et al. and Chang et al. [2,31]. The 1672 and $1523 \mathrm{~cm}^{-1}$ bands were assigned to the carbonyl and amino groups of the amide in ring $\mathrm{A}$, respectively. The frequencies at 1614 and $1581 \mathrm{~cm}^{-1}$ correspond

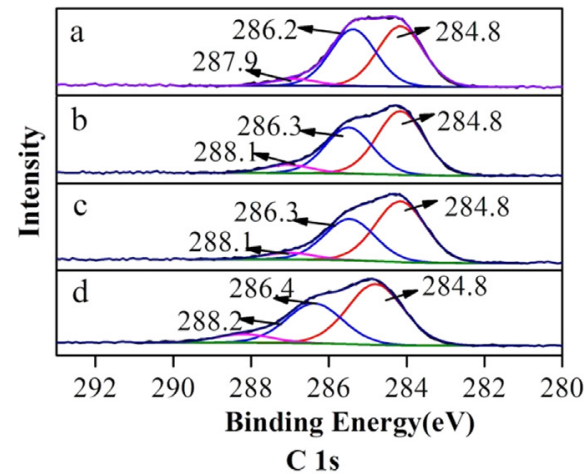

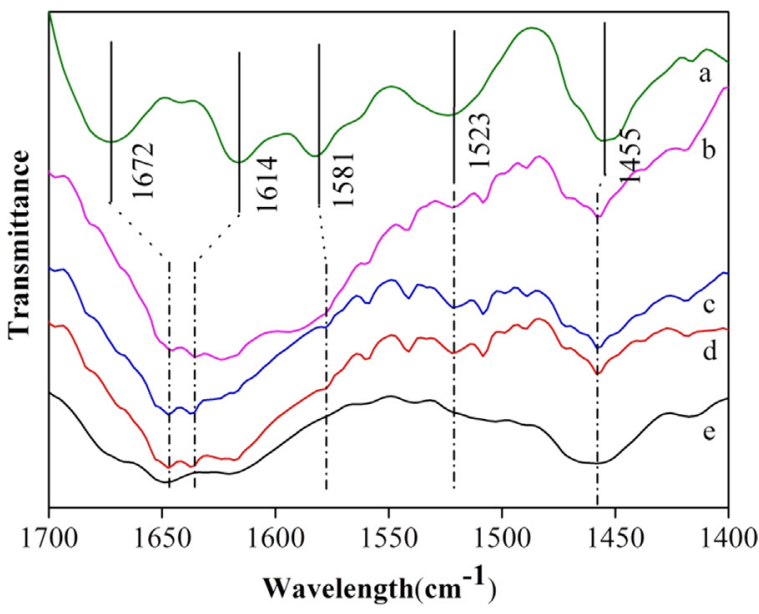

Fig. 5. FTIR spectrum of the virgin and TCs-loaded sorbents. (a) TC; (b) CTC-loaded sorbent; (c) OTC-loaded sorbent; (d) TC-loaded sorbent; (e) Fe-N,N-SBA15.

to the carbonyl groups in $\mathrm{A}$ and $\mathrm{C}$ rings or the amid- $\mathrm{NH}$, and the $1455 \mathrm{~cm}^{-1}$ band was assigned to the $\mathrm{C}=\mathrm{C}$ skeletal vibration. The spectra of the three TCs equilibrated with Fe-N,N-SBA15 were similar (Fig. 5b-d), indicating similar adsorption mechanisms for the molecules. The band at $1672 \mathrm{~cm}^{-1}$ for TC shifted to a lower frequency, and a decrease in the relative peak intensity of the $1523 \mathrm{~cm}^{-1}$ band showed that the carbonyl and amino group of the amide in ring A may have reacted with Fe (III) on the sorbent. The band at $1614 \mathrm{~cm}^{-1}$ shifted to a higher frequency, indicating that the carbonyl groups or the amid-NH in ring A may have been influenced by the complexation of TCs and Fe (III) on the sorbent. This was consistent with the complexation of TC and hydrous oxides of $\mathrm{Al}, \mathrm{Fe}[2,31]$. The intensity of the $1581 \mathrm{~cm}^{-1}$ band decreased, and the slight shift of the $1455 \mathrm{~cm}^{-1}$ band indicated that carbonyl groups of ring $\mathrm{C}$ or amid-NH in ring A of the TCs may form complexes with Fe (III) on the sorbent.

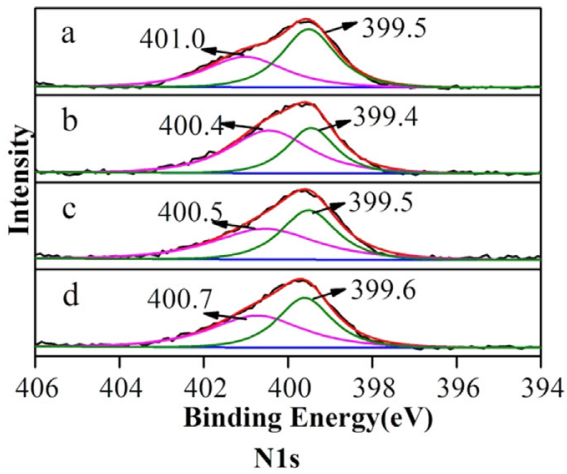

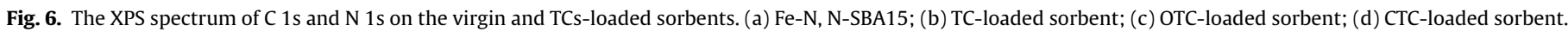


The high-resolution $\mathrm{C} 1 \mathrm{~s}$ and $\mathrm{N}$ 1s XPS spectra of the sorbents before and after adsorption of TCs are shown in Fig. 6. The $\mathrm{C} 1 \mathrm{~s}$ spectra could be divided into three individual component peaks: $287.9-288.2 \mathrm{eV}$ was attributed to $\mathrm{C}=\mathrm{O}$ or $\mathrm{O}-\mathrm{C}-\mathrm{O}, 286.2-286.4 \mathrm{eV}$ was associated with $\mathrm{C}-(\mathrm{O}, \mathrm{N})$, and $284.8 \mathrm{eV}$ was assigned to $\mathrm{C}-(\mathrm{C}$, $\mathrm{H})$. A comparison between sorbents before and after the reaction with TCs showed that the binding energy of $\mathrm{C}-(\mathrm{C}, \mathrm{H})$ peaks had no changes, a slight rise of binding energy was observed at $\mathrm{C}-(\mathrm{O}$, $\mathrm{N})$ from $286.2 \mathrm{eV}$ to $286.4 \mathrm{eV}$, and $\mathrm{C}=\mathrm{O}$ or $\mathrm{O}-\mathrm{C}-\mathrm{O}$ from $287.9 \mathrm{eV}$ to $288.2 \mathrm{eV}$. These shifts indicated that the electron distribution in the sorbent was disturbed, as evidenced by the increases in the electronic density around $\mathrm{C}$ in $\mathrm{C}-(\mathrm{O}, \mathrm{N})$ and $\mathrm{C}=\mathrm{O}$. The relative content of $\mathrm{C}-(\mathrm{C}, \mathrm{H})$ was observed to increase from $49 \%$ to $54 \%$, while $\mathrm{C}-(\mathrm{O}, \mathrm{N})$ decreased from $46 \%$ to $39 \%$ (Table S1). These results may be attributed to the interaction between Fe (III) of the sorbent and amide of TCs.

$\mathrm{N}$ 1s spectra exhibited two peaks: $399.5 \mathrm{eV}$ was assigned to the amino group, and the peak at $401.0 \mathrm{eV}$ was attributed to amino perturbed by Fe (III), which was also reported by Chen et al. and Zuo et al. [32,33]. After TC adsorption, the binding energy of $401.0 \mathrm{eV}$ decreased to $400.5 \mathrm{eV}$, and the relative content increased from $44 \%$ to $61 \%, 53 \%, 52 \%$ for TC, OTC and CTC, respectively (Table S1). This may be caused by interaction between the Fe (III) on the sorbent and the amino group of TCs. The amino group of TCs could form a $\mathrm{Fe}-\mathrm{N}$ covalent bond by donating a lone pair of electrons, causing an increase in the electron cloud density and lower binding energy of $\mathrm{NH}-\mathrm{Fe}$ on the sorbent. The results were consistent with those observed in the formation of Copper- $\mathrm{N}$ bonding [34]. Because the new $\mathrm{NH}-\mathrm{Fe}$ (III) bond formed, the relative content of the $401.0 \mathrm{eV}$ peak increased.

\section{Conclusions}

This article offered a new sorbent for the removal of TCs from aqueous solution. Due to the complexation interaction between Fe (III) and TCs, the TCs were adsorbed on Fe-N,N-SBA15. The pH influenced the adsorption of TCs significantly and the most effective $\mathrm{pH}$ was approximately 4.4-5.6. The adsorption of TCs on Fe-N,NSBA15 was fast and the isotherms were fitted with the Langmuir model perfectly. The thermodynamic parameters derived from the results showed that the adsorption process of TCs is spontaneous and endothermic. The differences in the constituent groups of the TCs induced slight changes in adsorption on the sorbent. All the results showed that the sorbent Fe-N,N-SBA15 showed excellent adsorption behavior for TCs and could be used as a potential sorbent for the removal of antibiotics.

\section{Acknowledgments}

This work was supported by the National Science Fund for Distinguished Young Scholars of China (Grant No. 51225805) and the National High Technology Research and Development program (Grants 2012AA062606) of China.

\section{Appendix A. Supplementary data}

Supplementary data associated with this article can be found, in the online version, at http://dx.doi.org/10.1016/j.colsurfa. 2015.02.018.

\section{References}

[1] X. Zhu, Y. Liu, F. Qian, C. Zhou, S. Zhang, J. Chen, Preparation of magnetic porous carbon from waste hydrochar by simultaneous activation and magnetization for tetracycline removal, Bioresour. Technol. 154 (2014) 209-214.

[2] C. Gu, K.G. Karthikeyan, Interaction of tetracycline with aluminum and iron hydrous oxides, Environ. Sci. Technol. 39 (2005) 2660-2667.
[3] A.K. Sarmah, M.T. Meyer, A.B.A. Boxall, A global perspective on the use, sales, exposure pathways, occurrence, fate and effects of veterinary antibiotics (VAs) in the environment, Chemosphere 65 (2006) 725-759.

[4] N. Le-Minh, S.J. Khan, J.E. Drewes, R.M. Stuetz, Fate of antibiotics during municipal water recycling treatment processes, Water Res. 44 (2010) 4295-4323.

[5] W. Ben, X. Pan, Z. Qiang, Occurrence and partition of antibiotics in the liquid and solid phases of swine wastewater from concentrated animal feeding operations in Shandong Province, China, Environ. Sci.: Process. Impacts 15 (2013) 870-875.

[6] Y. Luo, L. Xu, M. Rysz, Y. Wang, H. Zhang, P.J.J. Alvarez, Occurrence and transport of tetracycline, sulfonamide, quinolone, and macrolide antibiotics in the Haihe River Basin, China, Environ. Sci. Technol. 45 (2011) 1827-1833.

[7] X. Yang, R.C. Flowers, H.S. Weinberg, P.C. Singer, Occurrence and removal of pharmaceuticals and personal care products (PPCPs) in an advanced wastewater reclamation plant, Water Res. 45 (2011) 5218-5228.

[8] Y. Bai, W. Meng, J. Xu, Y. Zhang, C. Guo, Occurrence, distribution and bioaccumulation of antibiotics in the Liao River Basin in China, Environ. Sci.: Process Impacts 16 (2014) 586-593.

[9] D. Cheng, X. Liu, L. Wang, W. Gong, G. Liu, W. Fu, M. Cheng, Seasonal variation and sediment-water exchange of antibiotics in a shallower large lake in North China, Sci. Total Environ. 476-477 (2014) 266-275.

[10] E. Peltier, J. Vincent, C. Finn, D.W. Graham, Zinc-induced antibiotic resistance in activated sludge bioreactors, Water Res. 44 (2010) 3829-3836.

[11] A.B.A. Boxall, D.W. Kolpin, B. Halling-Sorensen, J. Tolls, Are veterinary medicines causing environmental risks? Environ. Sci. Technol. 37 (2003) 286A-294A.

[12] J.L. Martinez, Antibiotics and antibiotic resistance genes in natural environments, Science 321 (2008) 365-367.

[13] S.A. Sassman, L.S. Lee, Sorption of three tetracyclines by several soils: assessing the role of pH and cation exchange, Environ. Sci. Technol. 39 (2005) 7452-7459.

[14] J. Tolls, Sorption of veterinary pharmaceuticals in soils: a review, Environ. Sci. Technol. 35 (2001) 3397-3406.

[15] M.M. Barbooti, H. Su, P. Punamiya, D. Sarkar, Oxytetracycline sorption onto Iraqi montmorillonite, Int. J. Environ. Sci. Technol. 11 (2014) 69-76.

[16] M. Brigante, M.E. Parolo, P.C. Schulz, M. Avena, Synthesis, characterization of mesoporous silica powders and application to antibiotic remotion from aqueous solution. Effect of supported $\mathrm{Fe}$-oxide on the $\mathrm{SiO}_{2}$ adsorption properties, Powder Technol. 253 (2014) 178-186.

[17] O. Hanay, B. Yildiz, S. Aslan, H. Hasar, Removal of tetracycline and oxytetracycline by microscale zerovalent iron and formation of transformation products, Environ. Sci. Pollut. Res. 21 (2014) 3774-3782.

[18] R.A. Figueroa, A.A. Mackay, Sorption of oxytetracycline to iron oxides and iron oxide-rich soils, Environ. Sci. Technol. 39 (2005) 6664-6671.

[19] R. Otsuka, H. Yoshitake, Different modes of adsorptions of arsenate on silica grafted with $\mathrm{Fe}^{3+}$-coordinated silanes, J. Colloid Interface Sci. 415 (2014) $143-150$.

[20] T. Yokoi, Y. Kubota, T. Tatsumi, Amino-functionalized mesoporous silica as base catalyst and adsorbent, Appl. Catal. A: Gen. 421 (2012) 14-37.

[21] K.M. Parida, S.K. Dash, Adsorption of $\mathrm{Cu}^{2+}$ on spherical Fe-MCM-41 and its application for oxidation of adamantane, J. Hazard. Mater. 179 (2010) 642-649.

[22] D.Y. Zhao, J.L. Feng, O.S. Huo, N. Melosh, G.H. Fredrickson, B.F. Chmelka, G.D. Stucky, Triblock copolymer syntheses of mesoporous silica with periodic 50 to 300 angstrom pores, Science 279 (1998) 548-552.

[23] Y. Chao, W. Zhu, X. Wu, F. Hou, S. Xun, P. Wu, H. Ji, H. Xu, H. Li, Application of graphene-like layered molybdenum disulfide and its excellent adsorption behavior for doxycycline antibiotic, Chem. Eng. J. 243 (2014) 60-67.

[24] C. Zhao, J. Dai, Z. Zhou, X. Dai, Y. Zou, P. Yu, T. Zou, C. Li, Y. Yan, One-pot method for obtaining hydrophilic tetracycline-imprinted particles via precipitation polymerization in ethanol, J. Appl. Polym. Sci. 131 (2014)

[25] J.R.V. Pils, D.A. Laird, Sorption of tetracycline and chlortetracycline on K- and Ca-saturated soil clays, humic substances, and clay-humic complexes, Environ. Sci. Technol. 41 (2007) 1928-1933.

[26] Y.J. Wang, D.A. Jia, R.J. Sun, H.W. Zhu, D.M. Zhou, Adsorption and cosorption of tetracycline and copper(II) on montmorillonite as affected by solution $\mathrm{pH}$, Environ. Sci. Technol. 42 (2008) 3254-3259.

[27] M. Jia, F. Wang, Y. Bian, X. Jin, Y. Song, F.O. Kengara, R. Xu, X. Jiang, Effects of $\mathrm{pH}$ and metal ions on oxytetracycline sorption to maize-straw-derived biochar, Bioresour. Technol. 136 (2013) 87-93.

[28] Y. Zhao, F. Tong, X. Gu, C. Gu, X. Wang, Y. Zhang, Insights into tetracycline adsorption onto goethite: experiments and modeling, Sci. Total Environ. 470 (2014) 19-25.

[29] K.F. Hayes, J.O. Leckie, Modeling ionic-strength effects on cation adsorption at hydrous oxide-solution interfaces, J. Colloid Interface Sci. 115 (1987) 564-572.

[30] N.A. Oladoja, R.O.A. Adelagun, A.L. Ahmad, E.I. Unuabonah, H.A. Bello, Preparation of magnetic, macro-reticulated cross-linked chitosan for tetracycline removal from aquatic systems, Colloids Surf. B 117 (2014) 51-59.

[31] P.H. Chang, Z. Li, J.S. Jean, W.T. Jiang, Q. Wu, C.Y. Kuo, J. Kraus, Desorption of tetracycline from montmorillonite by aluminum, calcium, and sodium: an indication of intercalation stability, Int. J. Environ. Sci. Technol. 11 (2014) 633-644.

[32] J.C. Zuo, S.R. Tong, X.L. Yu, L.Y. Wu, C.Y. Cao, M.F. Ge, W.G. Song, Fe ${ }^{3+}$ and amino functioned mesoporous silica: preparation, structural analysis and arsenic adsorption, J. Hazard. Mater. 235 (2012) 336-342

[33] X. Chen, K.F. Lam, O Zhang, B. Pan, M. Arruebo, K.L. Yeung Synthesis of highly selective magnetic mesoporous adsorbent, J. Phys. Chem. C 113 (2009) 9804-9813

[34] L. Wu, H. Wang, H. Lan, H. Liu, J. Qu, Adsorption of Cu(II)-EDTA chelates on tri-ammonium-functionalized mesoporous silica from aqueous solution, Sep. Purif. Technol. 117 (2013) 118-123. 